\title{
ASSESSMENT TO THE PILE BEARING CAPACITY OF INJECTION PILE BASED ON PILE DRIVING ANALYZER AND RE-INJECTION TEST RESULTS (CASE: EASTKAL PENAJAM PROJECT)
}

\author{
Trihanyndio Rendy Satrya ${ }^{\mathrm{a}^{*}}$ and Musta'in Arifa
}

\begin{abstract}
Injection piling method was used as the main pile driving method at the three warehouses in the Eastkal Penajam project, Kalimantan, Indonesia. The sub-soil compositions are dominated by clay and sandy soil with very soft to medium consistencies. By using injection pile equipment, it is possible to measure the pile bearing capacity from the loading gauge. Since the soil is dominated by clay, the friction capacity overtime will be improved. For that purpose, the piles were re-injected again after 3, 10, 11, and 25 days. To establish the forecasting expression of pile bearing capacity enhancement for other piles, non-linear regression analysis was performed. To verify the result, pile driving analyzer (PDA) test for selected piles was carried out. The results from PDA test were further analyzed by using both direct fields reading in the PDA data logger and the Case Pile Wave Analysis Program (CAPWAP). A linear regression analysis was carried out to complete the blank data due to the field measurement limitation. In addition to the obtained field data, theoretical analysis of pile bearing capacity with Luciano Decourt method is carried out. From the comparisons of all data, it can be concluded that re-injection pile method provides the highest safety factor followed by PDA test, CAPWAP analysis, and theoretical design calculation with Luciano Decourt method.
\end{abstract}

Keywords: Re-injection, Pile Driving Analyzer, CAPWAP, safety factor, Eastkal, East Kalimantan.

\section{INTRODUCTION}

Three warehouses were built in the Eastkal Penajam Project located in East Kalimantan, Indonesia. From the Standard Penetration Test (SPT) and the boring log information, the sub-soil compositions are dominated by clay and sandy soil with very soft to medium consistencies. In detail, at elevation depth $\pm 0.00 \mathrm{~m}-14.00 \mathrm{~m}$ is found to be very soft clay; in $-14.00 \mathrm{~m}-16.00 \mathrm{~m}$ is sand, in -16.00 $\mathrm{m}-37.00 \mathrm{~m}$ is soft clay, in $-37.00 \mathrm{~m}-48.00 \mathrm{~m}$ is medium fine sand, in $-48.00 \mathrm{~m}-52.00 \mathrm{~m}$ is hard clay and from $52.00 \mathrm{~m}-55.00 \mathrm{~m}$ is very dense sand. The piles were square with $200 \mathrm{~mm}$ width and had the installed length varies depend on the loads acting on the piles. The investigated piles had lengths of $12 \mathrm{~m}, 17 \mathrm{~m}, 22 \mathrm{~m}$, and 26 m.

The piles were inserted into the soil by using injection pile equipment which has 120 Tons capacity. Injection pile is considered as the pile installation due to the better bearing capacity matters. Fellenius and Massarsch [1] stated that when using static pile installation with very slow penetration increment, the ground vibration along the pile and soil will be eliminated. By using injection pile equipment, it is possible to get the current applied stress on the pad from the dial pressure gauge. By knowing the pad area for pile injection, the bearing capacity of pile can be computed. However, since the underlying soil is dominated by clay, the bearing pile capacity from the friction between the soil and the pile surface is not yet fully working. Therefore, to evaluate the full bearing capacity of the soil, the piles were re-injected again at $3,10,11$, and 25 days. Hakam et. al [2] expressed that the increase of pile bearing capacity due to time delay was caused by the increase in the effective soil stress due to the dissipation of pore water pressure.

In addition to the pile bearing capacity obtained from the injection pile equipment, Pile Driving Analyzer (PDA)

${ }^{a}$ Lecturer in the Civil Engineering Department, Institut Teknologi Sepuluh Nopember, ITS Campus, Sukolilo, Surabaya 60111, Indonesia. Corresponding author email address: rendy_star@ce.its.ac.id equipment was used. There are two pile bearing capacity data obtained from the PDA equipment. The first data is obtained directly in the field for each hammer drop height observed and the second data is obtained from the Case Pile Wave Analysis Program (CAPWAP) program. Svinkin [3] stated that this program is the famous program in USA where principally using dynamic measurements in the pile head.

Moayedi et. al [4] stated that PDA test is more efficient than Static Loading test when there are many of piles requires to be investigated. However, the accuracy of PDA test is uncertain as it is categorized as dynamic measurement method and is dependent on many factors. Rybak et al [5] expressed that performing a bearing capacity test in short time and low cost will impact on the inaccuracy of bearing capacity prediction. On the contrary, Rajagopal et al [6] stated that the accuracy of dynamic load test is better than the static loading test.

In this paper, the pile bearing capacities obtained from re-injecting piles at certain amount of time delay, PDA test reading in the field with varying hammer drop height, PDA test software CAPWAP, and theoretical design formulation using Luciano Decourt method. For each pile bearing capacities obtained using the methods above, the safety factor is computed for comparisons purposes.

\section{RESEARCH SIGNIFICANCE}

This research investigates the pile bearing capacity enhancement due to time delay by using injection piling equipment. The time delay observed varies from $3,10,11$, and 25 days. In addition to the re-injected pile data, pile bearing capacity obtained from PDA test equipment also provided. Finally, classical theory to estimate the pile bearing capacity using Luciano Decourt method is presented for comparison purposes. For each pile bearing capacities obtained using the methods above, the safety factor is computed for comparisons purposes. 


\section{METHODOLOGY}

Data of the injected pile and PDA test were collected from three warehouses. The warehouse foundation consisted of group pile for the main structure and slab-onpile for the storage area inside the main structure. The observed pile lengths in the field varies from $12 \mathrm{~m}, 17 \mathrm{~m}$, $22 \mathrm{~m}$, and $26 \mathrm{~m}$. The pile injection equipment had a counterweight plus the body weight of total 120 tons. For each of the injected and re-injected piles, the pressure from the loading gauge are monitored and recorded.

The pile bearing capacity is computed by multiplying the pressure gauge data with pad area of the equipment which is in touch with the piles. The times delay in the observation is 0 day, 3 days, 11 days, and 26 days. It should be noted that due to limitation on the field measurement, regression analysis is used to estimate the full pile bearing capacity after 28 days of pile was being injected.

As for the PDA test, there are two ways the data can be obtained. The first one is by reading the field data using the four hammers drop height, and the second one is by using the CAPWAP software which is based on the obtained field data.

However, if the field data is incomplete, lower pile bearing capacity could be obtained. Finally, a classical formulation to compute the pile bearing capacity proposed by Decourt et al [7] is used for comparisons purposes which frequently used to estimate the pile bearing capacity in constructions.

\section{RESULTS AND DISCUSSION}

In this section, the results from the field data such as reinjection pile data, PDA test (both the direct field data and from CAPWAP software), and from the calculation in [7] are presented.

\section{A. PILE BEARING CAPACITY OBTAINED FROM INITIAL AND RE-INJECTION PILE (TIME DELAY EFFECT)}

Table 1 shows the penetration load (ultimate) at initial (0 day) and re-inject (with time delay) conditions. The time delay in the re-inject process varies and are 3,11 and 25 days. In Warehouse 01 (WH01), two piles with embedded length $12 \mathrm{~m}$ are re-injected after 3 and 11 days. In addition, three piles with $17 \mathrm{~m}$ depth are being re-injected after 3 and 11 days. The values of re-inject load at the age of 28 days shown in Table 1 are estimated value using the best fit regression analysis from the recorded available data at initial and with time delay. For piles with $12 \mathrm{~m}$ depth, the estimated increase in the pile bearing capacity after 28 days' time delay is $113.2 \%$ while for piles with $17 \mathrm{~m}$ depth is $112.2 \%$.

In Warehouse 02 (WH02), two piles with $12 \mathrm{~m}$ depth and one piles with $17 \mathrm{~m}$ depth were investigated. The same process as in WH01 piles to estimate the 28 days' pile bearing capacity was used. For piles with $12 \mathrm{~m}$ depth, the pile bearing capacity enhancement after 28 days' time delay varies from $114.8 \%$ to $172.3 \%$. For piles with $17 \mathrm{~m}$ depth, the increase in the pile bearing capacity is $229.8 \%$.

Table 1 Penetration Load (ultimate) from Re-Injection Process

\begin{tabular}{|c|c|c|c|c|c|c|c|c|}
\hline \multirow{3}{*}{ Warehouse } & \multirow{3}{*}{ Pile ID } & \multirow{3}{*}{$\begin{array}{l}\text { Time } \\
\text { Delay } \\
\text { (days) }\end{array}$} & \multirow{3}{*}{$\begin{array}{l}\text { Pile } \\
\text { Length } \\
\text { (m) }\end{array}$} & \multicolumn{4}{|c|}{ Re-Inject Load, Ultimate (Ton) } & \multirow{3}{*}{ Best Fit Equation } \\
\hline & & & & \multicolumn{4}{|c|}{ Age } & \\
\hline & & & & 0 days & 3 days & 11 days & 28 days & \\
\hline \multirow[b]{2}{*}{ WH-01 } & $\begin{array}{l}\mathrm{P} 1.21 \\
\mathrm{P} 1.15\end{array}$ & 3,11 & 12 & 15 & 25 & 30 & $31.98 *$ & $y=2.7877 \ln (x)+22.697$ \\
\hline & $\begin{array}{l}\text { P2.142 } \\
\text { P2.113 } \\
\text { P2.114 }\end{array}$ & $\begin{array}{c}3 \\
11 \\
11\end{array}$ & 17 & $\begin{array}{c}20 \\
20 \\
20 \\
\text { Avg. } 20 \\
\end{array}$ & $\begin{array}{c}35 \\
- \\
- \\
\text { Avg. 35 }\end{array}$ & $\begin{array}{c}- \\
40 \\
40 \\
\text { Avg. } 40\end{array}$ & $\begin{array}{c}- \\
- \\
- \\
\text { Avg. } 42.44^{*} \\
\end{array}$ & $y=3.0929 \ln (x)+32.143$ \\
\hline & & & & \multicolumn{4}{|c|}{ Age } & \\
\hline & & & & 0 days & 3 days & 10 days & 28 days & \\
\hline \multirow{3}{*}{ WH-02 } & P1.69 & \multirow{3}{*}{$\begin{array}{l}10 \\
10 \\
10\end{array}$} & \multirow{2}{*}{12} & 15 & $33.57^{*}$ & 37.5 & $40.85^{*}$ & $y=3.2572 \ln (x)+30.000$ \\
\hline & $\mathrm{P} 1.70$ & & & 15 & $27.38 *$ & 30.0 & $32.23 *$ & $\mathrm{y}=2.1715 \ln (\mathrm{x})+25.000$ \\
\hline & $\mathrm{P} 2.238$ & & 17 & 15 & $39.77 *$ & 45.0 & $49.47 *$ & $\mathrm{y}=3.0929 \ln (\mathrm{x})+32.143$ \\
\hline & & & & \multicolumn{4}{|c|}{ Age } & \\
\hline & & & & 0 days & 3 days & 25 days & 28 days & \\
\hline \multirow[t]{2}{*}{ WH-03 } & $\begin{array}{l}\text { P1.69 } \\
\text { P1.70 }\end{array}$ & \multirow{2}{*}{$\begin{array}{l}25 \\
25 \\
25\end{array}$} & 22 & 22.5 & $44.37 *$ & 52.5 & $52.93 *$ & $y=3.8343 \ln (x)+40.158$ \\
\hline & P2.239 & & 26 & 30 & $62.80 *$ & 75 & $75.65 *$ & $y=5.7515 \ln (x)+56.487$ \\
\hline
\end{tabular}

*Estimated regression

Unlike WH02, WH03 used different pile length. In WH03, two piles with $22 \mathrm{~m}$ depth and one pile with $26 \mathrm{~m}$ depth are investigated. The time delay for re-injection was
25 days. The increase in the pile bearing capacity estimated at 28 days' time delay for piles with $22 \mathrm{~m}$ depth is $135.2 \%$ while for piles with $26 \mathrm{~m}$ depth is $152.1 \%$. 


\section{B. PILE BEARING CAPACITY OBTAINED FROM PILE DRIVING ANALYZER (PDA) TEST}

Pile Driving Analyzer (PDA) test is aimed to predict the ultimate pile bearing capacity measured from various penetration height of hammer blow. Moayedi et. al [4] observed that the ultimate pile bearing capacity from PDA test was about $10 \%$ higher than static loading test. Haque et al [8] revealed that there was increase in shaft resistance of pile due to sequence of pile driving in clayey soils.

\section{B.1. PILE BEARING CAPACITY OBTAINED FROM THE CASE PILE WAVE ANALYSIS PROGRAM (CAPWAP)}

Table 2 shows the ultimate pile bearing capacity from CAPWAP program. Some data was incomplete due to the piles tip were broken during testing. From CAPWAP analysis, the maximum pile bearing capacity from the piles was 31.80 Ton. Considering the fact that the unconfined concrete strength $\left(f_{c}\right)$ of the piles obtained from the cylinder test (minimum) is $29 \mathrm{MPa}$, the elastic material strength of the piles could be in range of $35.51\left(0.3 \mathrm{f}_{\mathrm{c}} \mathrm{A}_{\mathrm{g}}\right)$ to 59.18 Tons $\left(0.5 \mathrm{f}_{\mathrm{c}} \mathrm{A}_{\mathrm{g}}\right)$. Hence, for piles in WH01 with embedded length into the soil $17 \mathrm{~m}$, due to broken piles and due to the fact that another piles tested with PDA can achieve 31.80 Ton, the ultimate pile bearing capacity of the piles could be higher than 31.8 Ton (CAPWAP) or 35.51 Ton (elastic pile material strength). It should be also noted that the maximum unbroken pile strength measured using CAPWAP was in close agreement with elastic pile strength material. Hence, it can be concluded that when the pile material was broken during testing, an elastic pile material strength can be used as an estimate of the piles bearing capacity. Nevertheless, the values from CAPWAP with broken piles are not included in the analysis.

Table 2 Ultimate load of pile bearing capacity obtained from CAPWAP analysis.

\begin{tabular}{|c|c|c|c|}
\hline Warehouse & Pile & Pile length (m) & Ultimate Load from CAPWAP (ton) \\
\hline \multirow{2}{*}{ WH01 } & P1.6 & 12 & 20 \\
\cline { 2 - 4 } & P2.142, P2.113 and P2.114 & 17 & N/A \\
\hline Slab on Pile at WH01 & P2.142, P2.113 and P2.114 & 17 & N/A \\
\hline \multirow{2}{*}{ WH02 } & P1.67 & 12 & 23.10 \\
\cline { 2 - 4 } & P2.192 & 17 & 23.20 \\
\hline Slab on Pile at WH02 & P2.192 & 22 & 30.30 \\
\hline \multirow{2}{*}{ WH03 } & P1.28 & 22 & 31.80 \\
\cline { 2 - 4 } & P1.29 & 26 & 31.80 \\
\hline Slab on Pile at WH03 & P2.241 & & \\
\hline
\end{tabular}

$\mathrm{N} / \mathrm{A}=$ not available

\section{B.2. PILE BEARING CAPACITY OBTAINED FROM PDA EQUIPMENT WITH VARYING HAMMER DROP HEIGHT}

In this section, pile bearing capacity obtained directly from the PDA equipment with varying hammer drop height is presented. In order to get the correct input into the CAPWAP program, data with varying hammer drop height should be carried out in the field. The hammer drop height should be investigated in the field are 0.5, 0.75, 1.0, and $1.5 \mathrm{~m}$. Table 3 shows the estimated pile bearing capacity with varying hammer drop height.
As seen in Table 3, there are values with a symbol "**, this tells that the values are estimated from linear interpolation and extrapolation. Linear forecasting was used since the data was not available. The relying foundation of using linear forecasting can be attributed to the fact that the energy absorbed by the piles due to hammer drop height was in the form of potential energy. This potential energy is well known to be function of linear height. Hence, using linear equation to interpolate and extrapolate the data is reasonable. In Table 3, it was also shown the best fit equation from the obtained data and it was shown that the best fit equation did show linear relation of the data.

Table 3 Pile bearing capacity from PDA equipment with varying hammer drop height

\begin{tabular}{|c|c|c|c|c|c|c|c|c|}
\hline \multirow{3}{*}{ Warehouse } & \multirow{3}{*}{ Pile } & \multirow{3}{*}{$\begin{array}{c}\text { Time } \\
\text { Delay of } \\
\text { PDA test }\end{array}$} & \multirow{3}{*}{$\begin{array}{l}\text { Pile } \\
\text { Length } \\
\text { (m) }\end{array}$} & \multirow{2}{*}{\multicolumn{4}{|c|}{$\frac{\text { PDA test, Ultimate (Ton) }}{\text { Height of hammer blow (m) }}$}} & \multirow{3}{*}{ Best Fit Equation } \\
\hline & & & & & & & & \\
\hline & & & & $0.5 \mathrm{~m}$ & $0.75 \mathrm{~m}$ & $1.0 \mathrm{~m}$ & $1.5 \mathrm{~m}$ & \\
\hline WH-01 & P1.6 & 28 days & 12 & 10 & $13.833 *$ & 18 & 24 & $y=14.0 x+3.333$ \\
\hline \multirow{2}{*}{ WH-02 } & P1.67 & 25 days & 12 & 10 & 10 & 17 & $26.33 *$ & $y=20.0 x-3.667$ \\
\hline & P2.192 & 32 days & 12 & 14 & $21 *$ & 28 & $42 *$ & $y=28.00 x+0.00$ \\
\hline \multirow{2}{*}{ WH-03 } & $\mathrm{P} 1.29$ & 18 days & 22 & 11 & $21.5^{*}$ & 32 & $53 *$ & $y=42.00 x-10.0$ \\
\hline & P2.241 & 17 days & 26 & 25 & $35.14 *$ & $45.27^{+}$ & $65.54 *$ & $y=40.54 x+4.73$ \\
\hline
\end{tabular}

*estimated from regression line

+estimated from the material capacity due to crushing of the upper file during impact 


\section{PILE BEARING CAPACITY OBTAINED FROM ANALYTICAL SOLUTION}

For comparison with the obtained field data either from injection pile equipment or PDA tests, analytical solution, using method in Decourt et al [7], is presented. From the SPT data, the sub-soil compositions are dominated by clay and sandy soil with very soft to medium consistencies. For details, at elevation depth $\pm 0.00 \mathrm{~m}-14.00 \mathrm{~m}$ is found to be very soft clay; in $-14.00 \mathrm{~m}-16.00 \mathrm{~m}$ is sand, in $-16.00 \mathrm{~m}$ $37.00 \mathrm{~m}$ is soft clay, in $-37.00 \mathrm{~m}-48.00 \mathrm{~m}$ is medium fine sand, in $-48.00 \mathrm{~m}-52.00 \mathrm{~m}$ is hard clay and from $-52.00 \mathrm{~m}$ $-55.00 \mathrm{~m}$ is very dense sand.

The pile bearing capacity was calculated by using method in Decourt et al [7]. The N-SPT value should be corrected for fine sand, silty sand and clayey sand. In detail, the $\mathrm{N}$ values should be corrected becomes N' values if the soil is located below the water level and the $\mathrm{N}$ value is more than 15 . To correct this $\mathrm{N}$ value data, Terzaghi and
Peck [9] method was used. The basic equation to estimate the pile bearing capacity $\left(\mathrm{Q}_{\mathrm{L}}\right)$ of the method in Decourt et al [7] comprises of the end bearing pile capacity $\left(\mathrm{Q}_{\mathrm{P}}\right)$ and the friction shaft bearing pile capacity $\left(\mathrm{Q}_{\mathrm{s}}\right)$. The general expressions for $\mathrm{Q}_{\mathrm{P}}$ and $\mathrm{Q}_{\mathrm{S}}$ in [7] are as follows:

$Q_{P}=\alpha q_{P} A_{P}$

$Q_{S}=\beta q_{S} A_{S}$

where $\mathrm{q}_{\mathrm{P}}$ is the average end bearing stress, $\mathrm{q}_{\mathrm{s}}$ is the average frictional shaft stress resistance, $A_{P}$ is the end tip pile area, and $A_{S}$ is the pile sleeve along the embedded depth of piles. The values for $\alpha$ (base coefficient) and $\beta$ (shaft coefficient) depend on to how the piles were inserted into the soil. For driven pile, the value for $\alpha$ and $\beta$ are unity. While for injection pile, the value for $\alpha$ is unity and the value for $\beta$ can be taken as 3 . Figure 1 shows the pile bearing capacity of driven pile with dimension $200 \times 200 \mathrm{~mm}^{2}$. The soil data is based on BH-1 N-SPT Data.

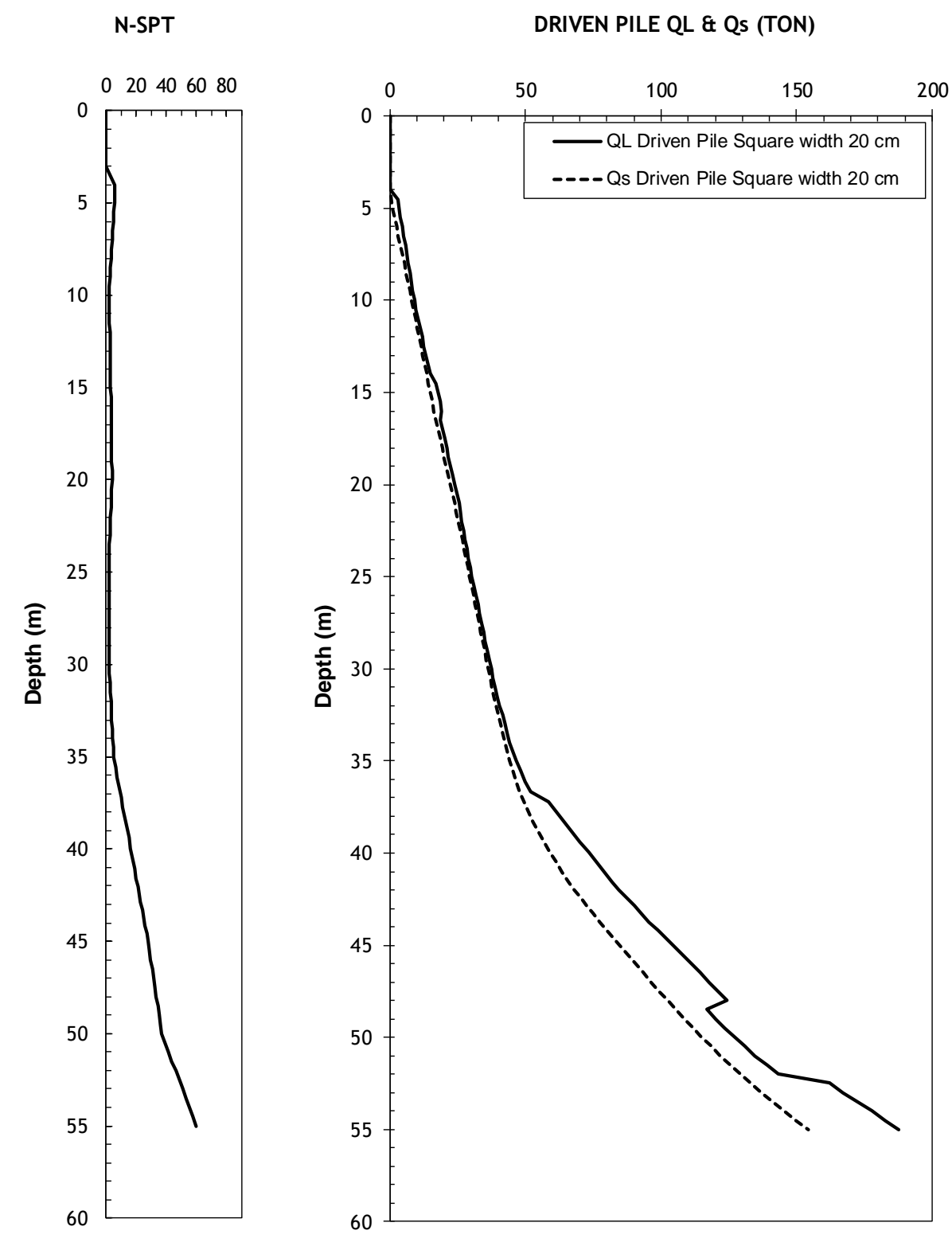

Figure 1 Axial Load Bearing Capacity Curve from BH-1 
The ultimate pile bearing capacity for $12,17,22$, and $25 \mathrm{~m}$ are 11.9, 19.3, 26.7 and 31.7 Tons, respectively. While the ultimate frictional pile bearing capacity for $12,17,22$, and $25 \mathrm{~m}$ are $10.8,17.8,25.3$, and 30.8 Tons, respectively. These computed data showed that the ultimate end pile bearing capacity for $\mathrm{BH}-1$ are only fractions of the ultimate pile bearing capacity and thus the pile can be said as frictional pile. From the analysis, the end bearing of piles can be significantly enhanced if the pile depth is below -35 $\mathrm{m}$ due to high consistency of sand soil.

\section{EVALUATION OF SAFETY FACTORS}

In this section, evaluation of safety factor against the working loads is presented. Table 4 shows the evaluation of safety factors from the re-injected pile test, PDA tests (direct data and CAPWAP analysis) and analytical solution using driven pile method [7] with $\alpha$ and $\beta$ are set to unity. From Table 4, the safety factor obtained from re-inject test is higher than both results from PDA test. This can be possible since some data obtained from the hammer drop height were incomplete which may affect the results from CAPWAP analysis.

Table 4 Evaluation of safety factors from re-injected pile test, PDA tests (direct data and CAPWAP analysis), and analytical solution [7] of driven pile method

\begin{tabular}{|c|c|c|c|c|c|c|c|c|c|c|}
\hline Warehouse & $\begin{array}{c}\text { Pile } \\
\text { Length } \\
{[\mathrm{m}]}\end{array}$ & $\begin{array}{c}\text { Service } \\
\text { Load } \\
\text { [ton] }\end{array}$ & $\begin{array}{c}\text { PDA Test } \\
\text { Direct Data } \\
\text { [ton] }\end{array}$ & \begin{tabular}{|c} 
PDA Test \\
Direct Data \\
{$[\mathrm{SF}]$}
\end{tabular} & $\begin{array}{c}\text { PDA Test } \\
\text { CAPWAP } \\
\text { [ton] }\end{array}$ & $\begin{array}{c}\text { PDA Test } \\
\text { CAPWAP } \\
{[\mathrm{SF}]}\end{array}$ & $\begin{array}{c}\mathrm{Re}- \\
\text { Inject } \\
\text { Test } \\
\text { [ton] }\end{array}$ & $\begin{array}{c}\text { Re- } \\
\text { Inject } \\
\text { Test } \\
{[\mathrm{SF}]}\end{array}$ & $\begin{array}{c}\text { Ultimate } \\
\text { Bearing } \\
\text { Capacity } \\
\text { [ton] }\end{array}$ & $\begin{array}{c}\text { Ultimate } \\
\text { Bearing } \\
\text { Capacity } \\
\text { [SF] }\end{array}$ \\
\hline \multirow{2}{*}{ WH-01 } & 12 & 7.95 & 24 & 3.018 & 20 & 2.515 & 31.98 & 4.022 & 11.9 & 1.50 \\
\hline & 17 & 10.77 & N/A & N/A & N/A & N/A & 42.44 & 3.940 & 19.3 & 1.79 \\
\hline $\begin{array}{l}\text { Slab on Pile } \\
(\mathrm{WH}-01)\end{array}$ & 17 & 21.92 & N/A & N/A & N/A & N/A & 42.44 & 1.936 & 19.3 & 0.88 \\
\hline \multirow{2}{*}{ WH-02 } & 12 & 8.00 & 26.33 & 3.291 & 15.10 & 1.887 & 32.23 & 4.028 & 11.9 & 1.49 \\
\hline & 17 & 11.03 & 42.00 & 3.807 & 23.20 & 2.103 & 49.47 & 4.485 & 19.3 & 1.75 \\
\hline $\begin{array}{l}\text { Slab on Pile } \\
\text { (WH-02) }\end{array}$ & 17 & 21.92 & 42.00 & 1.916 & 23.20 & 1.058 & 49.47 & 2.256 & 19.3 & 0.88 \\
\hline \multirow{2}{*}{ WH-03 } & 22 & 8.27 & 45.27 & 5.474 & 30.30 & 3.663 & 52.93 & 6.400 & 26.7 & 3.23 \\
\hline & 22 & 10.85 & 45.27 & 4.172 & 31.80 & 2.930 & 75.65 & 6.972 & 31.7 & 2.92 \\
\hline $\begin{array}{l}\text { Slab on Pile } \\
\text { (WH-03) }\end{array}$ & 26 & 21.92 & 45.27 & 2.065 & 31.80 & 1.450 & 75.65 & 3.451 & 31.7 & 1.45 \\
\hline
\end{tabular}

\section{E. DISCUSSION ON OTHER RESEARCH ON THE EFFECT OF TIME DELAY TO THE PILE BEARING CAPACITY}

Ghazavi and Ahmadi [10] noted that the pile bearing capacity can increase significantly during the first month and keep on growing up to nine months. Hence, there are possibilities that after one months, the pile bearing capacity obtained in Table 4 could be growing higher over time. However, by looking at the increase of the pile bearing capacity as shown in Table 1 , it can be inferred that overtime, the rate of increase in the pile bearing capacity reduces. Hence, to have a significance increase after onemonth time delay would be unlikely. By using the best-fit equation in Table 1 , it is possible to compute the rate of
On the other hand, analytical solution to estimate the pile bearing capacity by using the method in Decourt et al [7] shows to be much lower than either the PDA tests (direct data and CAPWAP analysis) and the re-inject pile data. Please note that the value for $\alpha$ and $\beta$ when driven pile formula in [7] is used would be equal to unity. If injection pile formula in [7] is used with the value for $\beta$ was changed to a higher number, say three, the estimated results would be higher.

However, by dividing the SF from analytical solution with SF from the re-inject test and by neglecting the contribution from the end bearing capacity, the value for the SF ratio would be higher than two. This means that for conservative reasons, the value for $\beta$ in [7] should be modified to at least not higher than two. It should be noted that from PDCA 2001, the minimum safety factor against working load obtained from the field is 1.9 . From the reinject pile investigation, it was found out that from the reinject pile test method, the minimum safety factor was 1.936. increase in the pile bearing capacity by taking the differentiation of the proposed equation in Table 1.

Hakam et. al [2] studies the increase in the pile bearing capacity dominated by very soft clay (up until $-14.0 \mathrm{~m}$ depth. The pile bearing capacity was investigated after 30 minutes. From their study, it was found out that there was increase in the sudden pile bearing capacity. One of the reasons in their finding is that the increase in the pile bearing capacity was mainly due to the pore water pressure dissipation. The longer the time delays, the more likely higher pore water is dissipated.

\section{CONCLUSIONS}

This paper has presented a detailed assessment on the pile bearing capacity due to time delays. There are four methods being investigated. The first method was using re- 
injection pile method with a certain time delay. The second method was using the PDA direct data in the field from the hammer drop test. The third method is using the PDA test results from CAPWAP analysis. The fourth method was using the analytical solution of driven pile method using the method in Decourt et al [7].

From the discussion on the increase of the pile bearing capacity using re-inject pile, it was found out that the minimum percentage increase of pile bearing capacity estimated at 28 days was $113.2 \%$ and the maximum percentage was $229.8 \%$. By neglecting the contribution of the end bearing capacity of the pile, a percentage increase of $100 \%$ in the pile bearing capacity can be directly related to the value of $\beta$ equal to two. While a percentage increase of $200 \%$ in the pile bearing capacity is equal to the value of $\beta$ as three. Hence, by using driven pile method for injection pile would give conservative results. But for safety reasons, from this study, the value for $\beta$ in injection pile method as in [7] should not be taken higher than two.

From the evaluation of safety factors, the results from PDA test were lower than the re-inject pile method. More research on the effect of time delay on the pile bearing capacity should be enriched in the future.

During the PDA test using drop hammer, it was possible the material of the pile was broken during test. This situation renders the output from the PDA could not be used. Hence, as an alternative, an elastic material strength up to $30 \%$ of the unconfined concrete strength of the material can be used for reference. Future possible avenue of research could be attributed by normalizing the pile bearing capacity from the data above and proposing one equation for pile bearing capacity estimate due to time delay effect for soft soil.

\section{REFERENCES}

[1] B. H. Fellenius dan K. R. Massarsch, "Comments on the Current and Future Use of Pile Dynamic Testing," Stress Wave, Lisbon, 2008, no. January 2008, hal. 14, 2008.

[2] A. Hakam, M. S. Asmirza, dan H. P. Andriani, "Additional bearing capacity of piles due to time delay of injection," Int. J. GEOMATE, vol. 15, no. 47, hal. 151-157, 2018, doi: 10.21660/2018.47.7235.

[3] M. R. Svinkin, "Engineering aspects in evaluation of pile capacity by dynamic testing," Struct. Congr. 2011 - Proc. 2011 Struct. Congr., vol. 41171, no. April, hal. 1686-1697, 2011, doi: 10.1061/41171(401)147.

[4] H. Moayedi, M. Mosallanezhad, dan R. Nazir, "Evaluation of Maintained Load Test (MLT) and Pile Driving Analyzer (PDA) in Measuring Bearing Capacity of Driven Reinforced Concrete Piles," Soil Mech. Found. Eng., vol. 54, no. 3, hal. 150-154, 2017, doi: 10.1007/s11204-017-9449-1.

[5] J. Rybak, D. Sobala, dan G. Tkaczynski, "Static and dynamic testing of driven piles in Poland," Appl. Stress. theory to piles Sci. Technol. Pract. Proc. 8th Int. Conf. Lisbon, Port. 8-10 Sept. 2008, no. January, hal. 615-618, 2008.

[6] Rajagopal, C. H. Solanki, dan Y. K. Tandel, "Comparison of static and dynamic load test of pile," Electron. J. Geotech. Eng., vol. 17 M, hal. 1905-
1914, 2012.

[7] L. Decourt, A. R. Quaresma, M. S. S. Almeida, dan F. Danziger, "Geotechnical investigation. In: Foundations: from theory to practice," $A B M S / A B E F$, Pini Publ., 1996.

[8] M. N. Haque, M. Y. Abu-Farsakh, dan C. Tsai, "Field investigation to evaluate the effects of pile installation sequence on pile setup behavior for instrumented test piles," Geotech. Test. J., vol. 39, no. 5, hal. 769-785, 2016, doi: 10.1520/GTJ20140259.

[9] K. Terzaghi dan R. B. Peck, Soil Mechanics in Engineering Practice. A Wiley International Edition, 1967.

[10] M. Ghazavi dan H. A. Ahmadi, "Time-Dependent Bearing Capacity Increase of Uniformly Driven Tapered Piles-Field Load Test," in The 6th Int. Conf. on Case Histories in Geotechnical Engg., Arlington, $V A, 2008$, hal. 1.66. 